\title{
Perbedaan Pengetahuan Ibu Hamil Tentang Skrining Hipotiroid Kongenital Sebelum dan Sesudah Diberikan Penyuluhan Di Puskesmas Tanah Tinggi Kota Tangerang Tahun 2019
}

\author{
Yenny Aulya*, Suprihatin, Dianoviani \\ Fakultas Ilmu Kesehatan, Universitas Nasional, Jakarta, Indonesia \\ Corresponding author: Yenny Aulya (yenny.aulya@ civitas.unas.ac.id) \\ Received: Mei, 20 2020; Accepted: June, 28 2020; Published: September, 12020
}

\begin{abstract}
ABSTRAK
Hipotiroid kongenital (HK) merupakan penyebab paling umum keterbelakangan mental. Skrining bayi baru lahir dapat mendeteksi adanya gangguan kongenital sedini mungkin, sehingga bila ditemukan dapat segera dilakukan intervensi secepatnya. Penelitian ini bertujuan untuk mengetahui perbedaan pengetahuan ibu hamil tentang Skrining Hipotiroid Kongenital sebelum dan sesudah diberikan penyuluhan di Pukesmas Tanah Tinggi Kota Tangerang tahun 2019. Penelitian ini menggunakan metode penelitian yaitu Pra-Eksperimen dengan pendekatan one group pretest-posttest design. Teknik pengambilan sampel menggunakan Purposive sampling dimana didapatkan hasil 58 responden. Pengumpulan data dalam penelitian ini menggunakan kuesioner. Kuesioner diberikan sebelum dan sesudah responden menerima ceramah. Analisa data dalam penelitian ini menggunakan uji Wilxocon Match Pair Test. Hasil penelitian ini menunjukan bahwa nilai rata-rata pengetahuan ibu hamil sebelum diberikan penyuluhan 65.774 setelah diberikan penyuluhan pengetahuan ibu hamil meningkat menjadi 82.843. Terdapat perbedaan pengetahuan yang signifikan sebelum dan sesudah diberikan penyuluhan dengan p-value 0,000 . Sebaiknya penyuluhan sering dilakukan saat ibu melakukan pemeriksaan untuk meningkatkan pengetahuan ibu.
\end{abstract}

Kata Kunci: Skrining Bayi Baru Lahir, Skrining Hipotiroid Kongenital, Pengetahuan, Pendidikan Kesehatan

This is an open-acces article distributed under the terms of the Creative Commons Attribution-ShareAlike 4.0 International License.

\section{PENDAHULUAN}

Hipotiroid kongenital adalah keadaan menurun atau tidak berfungsinya kelenjar tiroid yang didapat sejak bayi baru lahir. Hal ini terjadi karena kelainan anatomi atau gangguan metabolisme pembentukan hormon tiroid atau defisiensi iodium. Berdasarkan data yang dikumpulkan oleh Unit Koordinasi Kerja Endokrinologi Anak dari beberapa rumah sakit di Jakarta, Bandung, Yogyakarta, Palembang, Medan, Banjarmasin, Solo, Surabaya, Malang, Denpasar, Makassar, dan Manado, ditemukan 595 kasus HK yang ditangani selama tahun 2010.

Sebagian besar kasus ini terlambat didiagnosis sehingga telah mengalami gangguan pertumbuhan dan perkembangan motorik serta gangguan intelektual. Telaah rekam medis di 
klinik endokrin anak RSCM dan RSHS tahun 2012-2013 menunjukkan bahwa lebih dari 70\% penderita HK didiagnosis setelah umur 1 tahun, sehingga telah mengalami keterbelakangan mental yang permanen. Hanya 2,3\% yang bisa dikenali sebelum umur 3 bulan dan dengan pengobatan dapat meminimalkan keterbelakangan pertumbuhan dan perkembangan. Dengan demikian deteksi dini melalui skrining pada Bayi Baru Lahir sangat penting dan bayi bisa segera mendapatkan pengobatan (KEMENKES, 2014). Lawrence Green menjelaskan bahwa perilaku dilatarbelakangi oleh tiga faktor pokok salah satunya yaitu faktor predisposisi (predisposing factors), yang mempermudah atau mempredisposisi terjadinya perilaku seseorang, antara lain pengetahuan dan sikap seseorang.

Menurut Setiawati \& Dermawan (2008) Penyuluhan atau pendidikan kesehatan merupakan serangkaian upaya yang ditunjukan untuk peningkatan pengetahuan orang lain, mulai dari individu, kelompok, keluarga, dan peningkatan pengetahuan masyarakat agar terlaksana perilaku yang sehat. Di Kota Tangerang sendiri pemeriksaan skrining hipotiroid kongenital baru mulai dilakukan di beberapa Puskesmas PONED, salah satunya Puskesmas Tanah Tinggi. Dengan di lakukannya pemeriksaan Skrining Hipotiroid Kongenital diharapkan bagi anak yang terdeteksi Hipotiroid dapat di obati sejak dini. Dari latar belakang di atas, penulis tertarik untuk mengetahui mengetahui perbedaan pengetahuan ibu hamil tentang Skrining Hipotiroid Kongenital sebelum dan sesudah diberikan penyuluhan.

\section{METODE}

Penelitian ini menggunakan metode penelitian yaitu Pra-Eksperimen dengan pendekatan one group pretest-posttest design. Dimana penelitian ini dilakukan dengan cara memberikan pretest terlebih dahulu sebelum diberikan intervensi, setelah itu diberikan intervensi, kemudian dilakukan posttest (Hidayat, 2011).

Teknik pengambilan sampel menggunakan purposive sampling, yaitu suatu metode pengambilan sampel yang didasarkan pada suatu pertimbangan tertentu yang dibuatoleh peneliti sendiri, berdasarkan ciri atau sifat-sifat populasi yang sudah diketahui sebelumnya (Notoatmodjo, 2010).

Pengumpulan data dalam penelitian ini menggunakan kuesioner. Kuesioner diberikan sebelum dan sesudah responden menerima ceramah. Kuesioner telah diuji validitas dan reabilitas dengan nilai cronbach's alpha 0,898 . Analisa data dalam penelitian ini menggunakan uji Wilxocon Match Pair Test untuk membuktikan ada tidaknya perbedaan pengetahuan ibu hamil sebelum dan sesudah diberikan penyuluhan tentang Skrining Hipotiroid Kongenital.

\section{HASIL}

Perbedaan pengetahuan sebelum dan sesudah diberikan penyuluhan menunjukan bahwa adanya peningkatan nilai mean pretest dengan mean posttest dari 65,774 menjadi 82,843 . Sedangkan nilai standar deviasi pretest dengan standar deviasi posttest dari 17,3733 menjadi 6,8429. Dapat dilihat bahwa jumlah responden yang menjawab benar pada seluruh kelompok pertanyaan menjadi meningkat. Hasil penelitian menunjukkan bahwa ada nya peningkatan pengetahuan ibu hamil tentang Skrining Hipotiroid Kongenital sebelum dan sesudah diberikan penyuluhan. 


\section{Tabel 1}

Persentase Tingkat Pengetahuan Ibu Hamil Sebelum diberikan Penyuluhan Tentang Skrining Hipotiroid Kongenital di Puskesmas Tanah Tinggi Kota Tangerang Tahun 2019

\begin{tabular}{lcc}
\hline Pengetahuan & Jumlah & Persentase (\%) \\
\hline Kurang (0-55) & 16 & 27.6 \\
Cukup (56-75) & 26 & 44.8 \\
Baik (76-100) & 16 & 27.6 \\
\hline \multicolumn{1}{c}{ Total } & 58 & 100.0 \\
\hline
\end{tabular}

Pada Tabel 1 dapat dilihat data sebelum diberikan penyuluhan 27,6\% ibu hamil berpengetahuan kurang, 44,8\% ibu hamil berpengetahuan cukup, dan $27,6 \%$ berpengetahuan baik.

Tabel 2

Persentase Tingkat Pengetahuan Ibu Hamil Sesudah diberikan Penyuluhan Tentang Skrining Hipotiroid Kongenital di Puskesmas Tanah Tinggi Kota Tangerang Tahun 2019

\begin{tabular}{lll} 
Pengetahuan & Jumlah & Persentase (\%) \\
\hline Kurang (0-55) & 0 & 0 \\
Cukup (56-75) & 12 & 20.7 \\
Baik 76-100) & 46 & 79.3 \\
\hline Total & 58 & 100.0 \\
\hline
\end{tabular}

Pada Tabel dapat dilihat data sesudah diberikan penyuluhan tidak ada ibu hamil yang berpengetahuan kurang, 20,7\% ibu hamil berpengetahuan cukup, dan 79,3\% ibu hamil berpengetahuan baik.

Hasil dari penelitian didapatkan hasil posttest lebih baik dari pada hasil pretest, hal ini disebabkan karena adanya suatu perlakuan yaitu sebelum dilakukan posttest kepada ibu hamil diberikan penyuluhan tentang Skrining Hipotiroid Kongenital. Setelah diberikan penyuluhan ibu mendapatkan pembelajaran tentang Skrining Hipotiroid Kongenital. Sehingga ibu mendapatkan informasi baru yang mampu menambah pengetahuan responden (Notoadmodjo, 2010).

\section{Tabel 3}

Perbedaan Pengetahuan Ibu Hamil di Puskesmas Tanah Tinggi Kota Tangerang Sebelum dan Sesudah diberikan Penyuluhan

\begin{tabular}{llllll}
\hline & Minimum & Maksimum & Mean & Standar Deviasi & P Value \\
\cline { 1 - 5 } Pretest & 20.0 & 93.3 & 65.774 & 17.3733 & \multirow{2}{*}{0.000} \\
\hline Posttest & 73.3 & 93.3 & 82.843 & 6.8429 & \\
\hline
\end{tabular}

Berdasarkan Tabel 3 perbedaan pengetahuan sebelum dan sesudah diberikan penyuluhan menunjukan bahwa adanya peningkatan nilai mean pretest dengan mean posttest dari 65,774 menjadi 82,843 . Sedangkan nilai standar deviasi pretest dengan standar deviasi posttest dari 17,3733 menjadi 6,8429. Dapat dilihat bahwa jumlah responden yang menjawab benar pada seluruh kelompok pertanyaan menjadi meningkat.

Berdasarkan uji statistik dengan uji Wilxocon Match Pair Test di peroleh nilai sig. sebesar 0,000 $(<0,005)$ maka keputusannya adalah hipotesis nol $(\mathrm{Ho})$ ditolak yang berarti ada 
peningkatan pengetahuan ibu hamil tentang Skrining Hipotiroid Kongenital sebelum dan sesudah diberikan penyuluhan.

\section{PEMBAHASAN}

Berdasarkan hasil uji Wilxocon Match Pair Test didapatkan bahawa ada nya peningkatan pengetahuan ibu hamil tentang Skrining Hipotiroid Kongenital sebelum dan sesudah diberikan penyuluhan. Dapat dilihat dari hasil persentase tingkat pengetahuan sebelum diberikan penyuluhan $27,6 \%$ ibu hamil berpengetahuan kurang, $44,8 \%$ ibu hamil berpengetahuan cukup, dan $27,6 \%$ berpengetahuan baik. Sedangkan sesudah diberikan penyuluhan hasil presentase meningkat. Tidak ada ibu hamil yang berpengetahuan kurang, 20,7\% ibu hamil berpengetahuan cukup dan 79,3\% ibu hamil berpengetahuan baik.

Perbedaan pengetahuan bisa terjadi karena sebelumnya, ibu diberikan pertanyaan yang harus ibu jawab sesuai dengan apa yang ibu tahu, dan hasil dari pretest tersebut menggambarkan pengetahuan dasar yang dimiliki oleh responden. Setelah itu, ibu diberikan pendidikan kesehatan tentang Skrining Hipotiroid Kongenital dengan metode ceramah dengan alat bantu leaflet.

Disini peneliti menggunakan metode ceramah, alasan peniliti menggunakan metode ceramah dikarenakan metode ceramah merupakan cara dalam menyajikan penyuluhan melalui penuturan secara lisan atau penjelasan langsung kepada responden. Kelebihan dari metode ini murah dan mudah untuk dilakukan. Karena tidak memerlukan peralatan yang lengkap. Ceramah hanya mengandalkan suara peneliti, dengan demikian tidak terlalu memerlukan persiapan yang rumit. Tidak hanya itu, dalam proses ceramah ini memudahkan setiap ibu hamil untuk berinteraksi langsung dengan menanyakan hal-hal yang tidak ibu mengerti kepada pemberi materi (Sanjaya, 2011). Penyampaian informasi dipengaruhi oleh metode dan media yang digunakan yang mana metode dan media penyampaian informasi dapat memberikan efek yang signifikan terhadap peningkatan pengetahuan (Notoadmojo, 2007). Hal ini membuktikan bahwa metode ceramah efektif digunakan untuk meningkatkan pengetahuan ibu hamil tentang Skrining Hipotiroid Kongenital.

Dalam penelitian ini, peneliti menggunakan media leaflet, alasan peneliti menggunakan leaflet dikarenakan didalam leaflet terdapat gambar yang dapat membuat ibu tertarik untuk membacanya, bisa dibawa pulang sehingga ibu hamil dapat membacanya kembali dirumah. Leaflet juga mampu membantu ibu hamil agar lebih memahami apa yang dijelaskan oleh peneliti. Karena dalam hal ini, media leaflet media yang mengkombinasi antara fakta dengan gagasan secara jelas melalui gambaran sejumlah kata-kata, foto, gambar yang menarik dan ibu hamil tidak hanya bisa menggunakan pengindraan dengan mendengarkan akan tetapi para ibu hamil juga dapat menggunakan indra penglihatan yaitu dengan melihat dan membaca leaflet (Notoadmojo, 2010).

Dalam proses perubahan pengetahuan seseorang dapat mempelajari pengetahuan dengan apabila menggunakan lebih dari satu indera. $10 \%$ kita bisa mengingat dengan membaca, 20\% kita bisa mengingat dari yang kita dengar, 30\% dari yang kita lihat dan $80 \%$ dari apa yang kita ucapkan, dan $90 \%$ dari apa yang kita ucapkan dan lakukan. Dengan menggunakan metode ceramah dan media leaflet, responden diharapkan mampu meningkatkan pengetahuan sekitar $50 \%$ (Citerawati, 2012).

Hal ini sejalan dengan penelitian Tariqa (2017), dkk tentang penilaian pengetahuan, sikap dan praktik terhadap skrining bayi baru lahir untuk hipotiroid kongenital sebelum dan sesudah diberikan pendidikan kesehatan pada wanita di Rumah Sakit Pakistan. Berdasarkan hasil penlitian tersebut ada peningkatan yang signifikan dalam kesadaran wanita setelah intervensi (20\% menjadi sekitar 98\%). Demikian pula, 78,9\% yang setuju untuk memilih tes skrining untuk bayi baru lahir mereka setelah melahirkan dibandingkan dengan sebelum 
dilakukan intervensi terdapat 57,7\% wanita yang setuju memilih untuk tes skrining bayi baru lahir mereka.

Hal ini sejalan dengan penelitian Pani (2013) tentang pengaruh penyuluhan kelas prenatal plus terhadap pengetahuan dan sikap ibu hamil di wilayah kerja Puskesmas Mamboro Kecamatan Palu Utara. Berdasarkan hasil penelitian tersebut terlihat pretest, nilai mean 21, 75 dengan standar deviasi 3,297. Setelah dilakukan penyuluhan, Posttest nilai mean meningkat menjadi 32,31 dengan standar devisiasi 4,557. Disimpulkan bahwa ada pengaruh penyuluhan kelas prenatal plus terhadap pengetahuan dan sikap ibu hamil serta, ada perbedaan pengetahuan dan sikap ibu hamil pada kelas prenatal dan kelas prenatal plus.

Hal ini juga sejalan dengan penelitian Sari (2018), dkk tentang perbedaan pengetahuan perbedaan pengetahuan ibu sebelum dan sesudah diberikan penyuluhan tentang ASI Eksklusif di wilayah kerja Puskesmas Sidomulyo rawat inap Kota Pekanbaru. Berdasarkan hasil penelitian tersebut terlihat pretest, nilai mean 14,87 dengan standar deviasi 3,529. Setelah dilakukan penyuluhan, Posttest nilai mean meningkat menjadi 18,25 dengan standar devisiasi 1,945. Disimpulkan bahwa ada perbedaan tingkat pengetahuan ibu sebelum dan sesudah diberikan penyuluhann tentang ASI Eksklusif dengan kata lain ada perbedaan yang signifikan setelah dilakukan penyuluhan tentang ASI eksklusif.

Menurut peneliti penyuluhan merupakan salah satu cara memberikan pendidikan kesehatan. Penyuluhan sendiri dapat meningkatkan pengetahuan ibu hamil. Selain itu penyuluhan dapat dilakukan dimana saja dan kapan saja sehingga memudahkan pembicara. Media yang dibutuhkan juga tidak terlalu sulit, cukup hanya dengan menggunakan leaflet sudah bisa membantu pembicara menyampaikan informasi. Pengetahuan seseorang dipengaruhi oleh pendidikan, pekerjaan, umur, minat, pengalaman, kebudayaan lingkungan sekitar dan informasi. Dalam penelitian ini ibu hamil diberikan informasi melalui penyuluhan dan dari hasil penelitian yang sudah dilakukan, pengetahuan ibu hamil meningkat setelah diberikan penyuluhan.

\section{KESIMPULAN}

Berdasarkan hasil penelitian yang dilakukan kepada 58 responden di Puskesmas Tanah Tinggi Kota Tangerang Tahun 2019, diperoleh data pengetahuan ibu hamil tentang Skrining Hipotiroid Kongenital sebelum dan sesudah diberikan penyuluhan sebagai berikut:

1. Pengetahuan ibu hamil tentang Skrining Hipotiroid Kongenital sebelum diberikan penyuluhan didapatkan nilai rata-rata 65.774.

2. Pengetahuan ibu hamil tentang Skrining Hipotiroid Kongenital sesudah diberikan penyuluhan didapatkan nilai rata-rata 82.843 .

3. Terdapat perbedaan pengetahuan yang signifikan sebelum dan sesudah diberikan penyuluhan tentang Skrining Hipotiroid Kongenital pada ibu hamil di Puskesmas Tanah Tinggi Kota Tangerang.

\section{REFERENSI}

Anggraeni, D.M., \& Saryono. 2013. Metodologi Penelitian Kualitatif dan Kuantitatif dalam Bidang Kesehatan. Nuha Medika: Yogyakarta.

Arikunto, S. 2006.Prosedur Penelitian Suatu Pendekatan Praktik. Jakarta. Rineka Cipta.

Batubara, J.RL., AAP, B.T., Pulungun, AB. 2010. Buku Ajar Endrikinologi Anak, Edisi I, IDAI: Jakarta.

Citerawati, YW., 2012, Media Penyuluhan, www.e-bookpdf.org.com, diakses 10 Juni 2019

Corwin, EJ 2009, Buku Saku Patofisiologi, Jakarta: Buku Kedokteran EGC. 
Hidayat, AA. 2007. Metode Penelitian Kebidanan Teknik Andira Data. Salemba Medika : Jakarta.

Kemenkes R.I.2014.Pedoman Skrining Hipotiroid Kongenital. Jakarta: Kementerian Kesehatan Republik Indonesia.

Kosim, M. S., Yunanto, A., Dewi, R., Saroso, G. I., Usman, A., 2010. Buku Ajar Neonatologi Edisi 1. Jakarta: Badan Penerbit IDAI.

Mubarak, WI.2012. Promosi Kesehatan Untuk Kebidanan. Jakarta: Medika.

Nurfadillah. 2014. Gambaran Pengetahuan Ibu Menyusui Tentang Skrining Hipotiroid Kongenital di RSUP DR. Wahidin Sudirohusodo Makassar Tahun 2014. Skripsi, Fakultas Ilmu Kesehatan Universitas Islam Negeri Alaudin Makassar, Makassar

Notoatmodjo, S. 2010. Metodologi Penelitian. Jakarta: Rineka Cipta.

Notoatmodjo, S. 2012. Kesehatan masyarakat: ilmu dan seni. Jakarta: Rineka Cipta.

Pani, W, 2013, Pengaruh Penyuluhan Kelas Prenatal Plus Terhadap Pengetahuan dan Sikap Ibu hamil di Wilayah Kerja Puskesmas Mamboro Kecamatan Palu Utara Kota Palu Provinsi Sulawesi Tengah, Skripsi, Fakultas Kesehatan Masyarakat Universitas Hasanuddin, Sulawesi.

Sabarguna.2012.Penelitian Operasional untuk Pembuatan Skripsi,Jakrta: Nulisbuku

Sari, TW., Wulandari, FS., Hidayat, MH., Amelia, N., Nasution, S., Yuriati, Y. 2018. Perbedaan Pengetahuan Ibu Hamil Sebelum dan Sesudah Diberikan Penyuluhan Tentang ASI Eksklusif di wilayah Kerja Puskesmas Sidomulyo Rawat Inap Kota Pekanbaru. Collaborative Medical Journal (CMJ) Vol 1 No 2 Mei 2018.

Setiawati, S., Dermawan AC. 2008. Media Pembelajaran Pendidikan Kesehatan. Yogyakarta: Gala Ilmu Semesta

Sastroasmoro, Sudigdo., Ismael, Sofyan. 2008. Dasar-dasar Metodologi Penelitian Klinis.Edisi ke-3. Jakarta: Sagung Seto.

Sudoyo, AW., Setiyohadi, B., Alwi, I., Simadibrata, M., Setiati, S. 2009. Buku Ajar Ilmu Penyakit Dalam Jilid II edisi V. Jakarta: Interna Publishing

Sujarweni. 2012. SPSS untuk Para Medis. Yogyakarta. Grava Media

Syafrudin., Fratidhina, Y. 2009. Promosi Kesehatan Untuk Mahasiswa Kebidanan. Jakarta: Trans Info Media

Tariq, B., Ahmed, A., Habib, A., Turab, A., dkk. 2017. Assessment of knowledge, attitudes and practices towards newborn screening for congenital hypothyroidism before and after a health education intervention in pregnant women in a hospital setting in Pakistan. In Health 